\title{
Modernismo frente a noventa y ocho: el caso de las andanzas de Unamuno
}

\author{
RICHARD A. CARDWELL \\ Universidad de Nottingham
}

Los ensayos sobre el excursionismo de Miguel de Unamuno, posteriormente recogidos en dos tomos -Por tierras de España y Portugal (1911) y su continuación, Andanzas y visiones españolas $(1922)^{1}-$ forman un remanso crítico. Con la excepción de un solo crítico, quien ha subrayado la importancia del tema del excursionismo en el movimiento noventayochista en España ${ }^{2}$, estos ensayos se ven casi completamente desatendidos en la crítica unamuniana. Es una omisión extraña no sólo por su cantidad sino también porque revelan muchas de las conocidas (y muy estudiadas) obsesiones del profesor salmantino $\mathrm{y}$, de modo quizás más importante, algunas de las preocupaciones intelectuales más destacadas de la edad de Unamuno y su generación.

1. «En 1911 publiqué [...] Por tierras de Portugal y de España. Constituíanlo veintiséis relatos de excursiones por ciudades y campos de la Península Ibérica y las islas Canarias. Y ahora recojo, [...] en este volumen [...] relatos de otras nuevas excursiones", Prólogo a Andanzas..., O.C., I, 601. Cito siempre por el tomo I de la edición Afrodisio Aguado, Madrid, 1958-61, publicada por Vergara (Barcelona).

2. Ver H. Ramsden (ed.), J. Martínez Ruiz, La ruta de don Quijote, Manchester University Press, 1966; "The Spanish Generation of 1898", Bulletin of the John Rylands University Library of Manchester, 56, 1974, 463-91, 57, 1974, 167-95 (JRUL) y The 1898 Movement in Spain, Manchester University Press, $1974(H R)$, reproducido en F. Rico, Historia y crítica de la literatura española, Barcelona, Editorial Crítica, 1982, tomo 6; J.C. Mainer, Modernismo y 98. 
Fue Unamuno un viajero infatigable. Su deseo de "conocer España" le llevó a peregrinar y sus viajes le proporcionaron los datos necesarios para una serie de ensayos que escribió a lo largo de un cuarto de siglo. En estos ensayos se revelan una obsesión personal y una curiosidad intranquila que formaron parte de una obsesión generacional. Apareció, tempranamente en el siglo anterior, una boga por "descubrir España" entre los románticos europeos; la moda nacional, se puede decir, empezó más tarde entre los hombres de la Institución Libre de Enseñanza y, especialmente, con Francisco Giner de los Ríos. Su influencia fue poderosa: sobre Antonio Machado, quien admitió en "En tren" (CX, Campos de Castilla, 1912) que "Yo, para todo viaje / [...] voy ligero de equipaje. [...] ;Este placer de alejarse!», sobre Ortega y Jiménez. La intención fue descubrir los rincones olvidados del país, pero también fue el deseo de huir de una realidad presente hacia un mundo de ensueño e ilusión: "siempre nos hace soñar", escribió Machado, y, a continuación en "Otro viaje» (CXXVII), nos habló de «este triste insomnio mío! / jeste frío / de un amanecer en vela!». Se trata, como veremos, de dos intenciones: una ligada a un conocimiento más profundo del campo, la otra a un modo muy especial de contemplar esta realidad, de contemplarla por el prisma de un estado de mente ni despierto (mediante la lógica) ni completamente dormido (mediante el sueño ilógico). La busca de la realidad geográfica española se revela a veces como la busca de algo irreal como admitió el propio Unamuno en 1936 al mirar atrás hacia sus Andanzas:

«Andar y ver» -se dice-. Y el que esto os dice ha publicado una colección de relatos de excursiones con el título de Andanzas y visiones españolas. Pero es más lo que ha soñado que lo que ha visto. Y sobre todo lo que ha soñado ver (1112).

Son aspectos que destacan entre esta generación de escritores finiseculares ${ }^{3}$. También una actitud intelectual con énfasis sobre las filosofías científicas del evolucionismo. Así, otro contemporáneo, José María Salaverría, en su Vieja España: Impresión de Castilla de 1907:

Me asomé a la ventanilla [del tren] y vi la profundidad de la noche, la extensión desolada de la llanura. ¡Cuán grave y expresiva era aquella planicie castellana, vieja patria del Cid, cuna del españolismo! Iba yo a conocer el secreto de una tierra de dominadores; iba a sentir el aliento

3. El estudioso encontrará la misma mezcla de los aspectos sentimentales (emocionales) y místicos (espirituales) en Ortega ("Tierras de Castilla", 1911); en Azorín (La voluntad, 1902; Castilla, 1912; en Baroja, Camino de perfección, 1902; etc.) 
de un país antiguo que imprimió en el mundo tan honda y duradera huella; quería desentrañar el misterio de aquella tierra esquilmada, rasa y humilde, que había sabido sujetar a su feudo otras tierras más ricas, más ágiles y mejor dotadas por la naturaleza. (pág. 5).

Estas facetas las compartió también Unamuno: veta sentimental para conocer su Patria en un contacto físico con el campo; veta espiritual como resultado de la contemplación de ella; búsqueda intelectual de algo latente en el campo y en el pueblo mismos (ver 443, 633 y 690). Escribió Unamuno en 1913:

Lo que va a seguir son notas de un curioso excursionista, que toma lo que ve y observa al azar de sus correrías como punto de partida para sus reflexiones, tal vez algo arbitrarias. (1913: 694)

Sin embargo, las reflexiones unamunescas no son ni más ni menos arbitrarias que las de Ortega, Azorin o Machado.

Empiezo con una análisis de la última veta, la veta determinista. El profesor Ramsden señala el énfasis noventayochista sobre «el carácter inalterable del pueblo rural español" y su "nueva sensibilidad hacia el paisaje el cual, supuestamente, lo habría formado [tal carácter] y un nuevo deleite en varios aspectos de la vida provincial en la cual, supuestamente, este carácter se había revelado" ( $H R, 141)$. Sugiere Ramsden, en este estudio y en otro más corto pero no menos poderoso en su argumentación ( $J R U L$ ), que la mayor fuerza intelectual que influyó sobre los escritores del 98 fue el determinismo conservador, rural y psicológico de Hipólito Taine. En breve, sostiene Ramsden que los hombres de la generación del 98 (Unamuno, Ganivet, Machado, Azorín, Baroja, Ortega) todos se «concentraron sobre el problema de España: la grandeza anterior, decaimiento presente y un resurgimiento futuro posible»; que "el problema de España es primariamente un problema psicológico: España [...] carece de un principio básico que la guíe (JRUL, 41). La búsqueda de un núcleo-guía básico puede descubrirse "mediante un auto-conocimiento colectivo". Bajo la complejidad y lo difuso del carácter queda «una base firme de entendimiento" (lo que llama Unamuno un "núcleo castizo") que se descubre "en todas las manifestaciones de la cultura de una nación pero que se revela más inmediatamente en el carácter del pueblo rural ordinario e inalterable [...] especialmente en el campo [donde] [...] se reconoce la influencia formativa del medio físico. Es allí en particular donde se encuentra la clave del carácter nacional, y de ahí, también de la historia y de la cultura nacionales» (JRUL, 42). Para Rams- 
den el problema de España puede ser una característica básica, pero no es, sugiere, "distintiva» (JRUL, 44). "Lo que distingue a los escritores del 98 de sus predecesores no es su preocupación por el problema, sino su reacción frente a él» (JRUL 44$)$. Unamuno ya había explorado este problema intelectual en En torno al casticismo (1895). Por tierras y Andanzas son, en un sentido, continuaciones de esta exploración y búsqueda unamunesca de raíces. Pero en el sentido de que el viajar es también un modo de huir ofrecen, por otra parte, un modo de auto-descubrimiento, la búsqueda de uno mismo. El excursionismo, así, es una respuesta a necesidades intelectuales tanto como emocionales. Volveremos sobre ello más tarde.

El viajar, entonces, ofreció a Unamuno y a sus contemporáneos la oportunidad de descubrir ese "carácter" y de ponerse en contacto íntimo con el paisaje español y su pueblo. El viajar les suministra la visión buscada, visión basada en el determinismo, de «esta nuestra inalterable y casi desconocida España". En el ensayo, apropiadamente titulado "Excursión», escrito en 1909 y recogido en Por tierras, admitió Unamuno que

Estas excursiones no son sólo un consuelo, un descanso y una enseñanza; son además, y acaso sobre todo, uno de los mejores medios de cobrar amor y apego de la tierra. (1909: 504)

Con sus contemporáneos y los románticos que le precedieron Unamuno odió las ciudades grandes: «Tengo miedo y aversión a las grandes ciudades", reveló en $1908^{4}$. En sus ensayos también se encuentran sugerencias que se refieren a una búsqueda de índole espiritual casi mística. Más directamente se trata del fluir inexorable del tiempo, tema destacado en la literatura finisecular. Pero más explícitamente expresa el autor su deseo de "conocer España», de explorar "el sentimiento de la continuidad en el cuerpo social", el carácter inalterable del campo y su pueblo. Pero también busca un norte, así que la búsqueda de raíces deterministas y de su propio ser se ven íntimamente ligadas. En En torno al casticismo (1895) Unamuno había dado énfasis a las realidades físicas de Castilla como clave de una identidad básica, resistente al tiempo. Para Unamuno, como ha señalado Ramsden, Castilla, la región de paisajes más distintos, fue, según el punto de vista determinista unamunesco, la clave del carácter. dis-

4. Ver también 1913: 683 y 1921: 832. 
tintivo nacional. Así, también su historia y cultura, productos consecuentes de la misma causalidad determinista. En Por tierras escribió en 1909:

En el aspecto íntimo del arte, para el que busca sensaciones profundas, para el que tiene el espíritu preparado a recibir la más honda revelación de la historia eterna, os digo que lo mejor de España es Castilla, y en Castilla pocas ciudades, si es que hay alguna, superior a Avila. (494-95)

Anda uno por dondequiera, continúa Unamuno, para distraerse o divertirse, "pero el que quiera columbrar lo que pudo antaño haber sido, vivir con el fondo del alma, ése que vaya a Avila; que venga también a Salamanca». Pero a pesar de tanto comentario y énfasis sobre "un alma nacional», la base de su búsqueda en En torno y demás trabajos es para Unamuno el cuerpo de España. Forja el profesor salmantino una combinación fácil entre lo espiritual y una estructura orgánica escondida. La psicología como estudio de lo interior espiritual y como estudio científico materialista supo combinar el idealismo decimonónico con el positivismo finisecular. Unamuno repetidamente se refiere a estructuras internas orgánicas. Así expresa su «visión de ensueño» en el idioma de las ciencias físicas:

Ciudad, como el alma castellana, dermatoesquelética crustácea, con la osamenta -coraza- por de fuera, y dentro de la carne, ósea también a las veces. Es el castillo interior de las moradas de Teresa, donde no cabe creer sino hacia el cielo. Y el cielo se abre sobre ella como la palma de la mano del Señor. (1922: 844; y ver también 1912: 660)

Se ve a las claras la meta que busca Unamuno: un núcleo de paz y fe, raíces y Dios. Ya que siente una fe debilitada busca confirmación por medios más rigurosos (en la ciencia), y por medios no asequibles a la lógica (en la imaginación).

¿Y qué evoca? Realidades físicas, medio ambiente, carácter colectivo, cultura (historia y literatura) y sentimientos y deseos personales. Se encuentra, entonces, la expresión de una armonía básica entre estos temas, temas que ya había explorado en En torno ${ }^{5}$.

Pero, por estas fechas, el determinismo unamunesco se ve menos explícito. Cuando, en sus ensayos tempranos, se hace uso de una

5. Azorín también había expresado este conjunto de obsesiones en la misma época: «La unión suprema e inexpresable de este paisaje [de España] con la raza, con la historia, con el arte, con la literatura de nuestra tierra [...]; un paisaje concordando íntima y espiritualmente con una raza y una literatura». (1913: OC, II, 1155-7). 
serie de términos precisos que pertenecían a las ciencias evolucionistas -el pueblo español como "producto de una larga selección", "hecho a la inclemencia del tiempo»- (rasgos que persistieron en Por tierras), ahora escribe haciendo uso de comparaciones, sugerencias, yuxtaposiciones, metáforas, símiles y, de vez en cuando, en plena moda simbolista, de paisajes del alma donde proyecta su propio humor sobre el paisaje contemplado. En este aspecto se nota una convergencia en vez de enfrentamiento entre Modernismo y Noventayocho. Cuando anteriormente se expresó por medio de afirmaciones claras y sin trabas, de índole determinista, en estos ensayos un lugar preferido le suscita un torrente de reflexiones, meditaciones y comentarios sobre estos aspectos. En realidad su lenguaje se ha hecho más poético, más auto-consciente. Es un cambio que se comentará luego.

La búsqueda emocional y la auto-proyección le impulsan a recordar a Obermann (significativamente una figura romántica norteña antes que española). Sin embargo, mientras indaga las raíces españolas, está muy dispuesto a pensar en los productos del medio ambiente determinista ante sus ojos: la realidad física de Medina del Campo provoca pensamientos de Isabel la Grande -y Santa Teresa- y las dos -Medina e Isabel- se hacen una (1912: 633). Pero no es el castillo (realidad física) ni la que, supuestamente, esta realidad ha creado -Isabel- los que sienten resignación. Es el propio autor que contempla una supuesta veta determinista en el medio ambiente, una historia y cultura formadas por esa veta, y que también se contempla en el paisaje que mira. Se encuentra el mismo proceso cuando llega al Escorial y recuerda a Fray José de Sigüenza (1912: 645) o cuando contempla la Castilla de la meseta que le evoca al Cid y se unen en su mente el paisaje y el Poema del Mío Cid (1916: 742). En «Salamanca» (1914) escribe Unamuno:

No puedo evitar el ponerme en mis escritos, y como nadie es más que el producto de la sociedad en que vive y de la que vive; como todos somos condensación del ambiente en que vivimos, todo el que acierta a ponerse en sus obras pone a su patria, chica y grande, en ellas. (1914: 720)

El viajar es auto-proyección, pero también es una búsqueda de un carácter colectivo, un modo de descubrir las raíces nacionales (y personales) de la raza:

Recorriendo estos viejos pueblos castellanos, tan abiertos, tan espaciosos, $\tan$ llenos de un cielo lleno de luz, sobre esa tierra, serena y reposada, junto a estos pequeños ríos sobrios, es como el espíritu que se siente atraído por sus raíces a lo eterno de la casta. (1912: 640) 
En las provincias y en las vidas del humilde pueblo ordinario hallará la dirección y el núcleo que busca:

Es sumergirse en el paisaje lo que nos hace recobrar la fe en un dichoso porvenir de la Patria. [...] La primera honda lección de patriotismo se recibe cuando se logra cobrar conciencia clara y arraigada del paisaje de la patria, después de haberlo hecho estado de conciencia, reflexionar sobre éste y elevarlo a idea. (1915: 737)

Se puede seguir citando de «Frente a los negrillos», artículo importantísimo entre los escritos de Únamuno. Y volveremos sobre sus últimas frases. Lo que busca es el carácter permanente e inalterable que ha formado al pueblo, la cultura y la historia de España; también sus antiguas ciudades, León, Salamanca, Avila (670, 415, 721, 833 y 496). «La búsqueda unamunesca de España [...] fue también una búsqueda de raíces personales. El investigador de los destinos nacionales [...] no fue meramente un observador; el sujeto y objeto de su estudio se habrian fusionado. La busca de la "roca viva" de España fue a la vez la busca de la "roca viva" propia" ( $H R, 173)$. Como confesó el propio Unamuno, "una ciudad desde el centro de la cual no se puede llegar a pie en cosa de un cuarto de hora al campo libre, es una ciudad que no responde a mis más íntimas necesidades espirituales». (1913: 683)

En lo que acabo de sostener hasta este punto he querido confirmar los argumentos expresados - para mí convincentes- en dos estudios del profesor Ramsden, especialmente en The 1898 Movement in Spain.

Ahora, se trata de analizar la veta espiritual como resultado de la contemplación del campo. He sugerido, siguiendo la tesis de Ramsden, que para Unamuno el viajar también expresa la busca de sí mismo. En la relación estrecha que establece entre su propio ser -o mejor sus sentimientos y emociones-y su medio ambiente descubrimos el profundo colorido romántico del lenguaje unamunesco y su modo de pensar. Quizás, más precisamente, el discurso romántico de Unamuno es de origen europeo norteño. Claro es que comparte con sus antecesores románticos españoles -Espronceda y Larra- la nota de interrogación metafísica. Pero la manera en que sobrepone su humor sobre el paisaje, la naturaleza como portadora de las obsesiones del escritor, la preferencia por paisajes bravos y montañosos y efectos atmosféricos impresionantes, el énfasis sobre la soledad y una comunión sensual (tanto como emocional y mental) con un ente espiritual 
omnipresente, todos estos aspectos pertenecen a la manifestación europea del norte de la experiencia romántica, notablemente, la de los poetas ingleses lakistas (refiriéndose a ellos emplea Unamuno la palabra musings), los románticos alemanes, el escritor francés, Senancour (cuyo Obermann fue libro de cabecera de Unamuno) y el ensayista y poeta suizo Henri-Frédéric Amiel. Aumentó rápidamente en España el interés por los románticos alemanes desde los años 1860 y especialmente en los 1890. La importancia de este fenómeno en la formulación de la veta simbolista del Modernismo, la segunda fase de la época de Helios, como he señalado ${ }^{6}$, fue trascendental. Como veremos, Unamuno no se vio enteramente divorciado de estos desarrollos estéticos a pesar de su muy pregonada antipatía al Modernismo. El contacto con la naturaleza le trae un alivio espiritual y físico:

El cuerpo se limpia y restaura con el aire sutil de aquellas alturas [la sierra de Gredos] y aumenta el número de glóbulos rojos [...] pero el alma también se limpia y restaura con el silencio de las cumbres (1911: 609)

Pero da más énfasis a lo espiritual: «Qué silenciosa oración allá en la cumbre...?» (609). También destaca la fuga de una realidad hostil y de la ciudad odiada.

Se nota aquí una típica paradoja unamunesca: como buen romántico es un solitario, no le gusta la compañía de sus prójimos y prefiere comunicarse con su desasosiego en las altas cumbres. Pero como determinista necesita a los hombres, encarnaciones del medio ambiente y las fuerzas de la casualidad determinista. Y resuelve la paradoja mediante la idea romántica y rousseauniana de la inocencia y nobleza del hombre primitivo. Para Unamuno el campesino humilde es preferible al hombre de frac o al político ramplón de la Corte. Y saca una enorme satisfacción y alivio espiritual de sus solitarias excursiones exactamente como otros de su generación (423 y 438) ${ }^{7}$.

6. Ver los siguientes estudios míos: las ediciones de Ricardo Gil, La caja de música y Francisco A. de Icaza, Efímeras \& Lejanías, Universidad de Exeter, Exeter Hispanic Texts, III, 1972 y XXXVI, 1983; "Ricardo Gil y el problema del modernismo» y "Cómo se hace un poema simbolista: El caso de Antonio Machado", ambos en las Actas del Congreso Internacional sobre el Modernismo español e hispanoamericano: sus raíces andaluzas y cordobesas, (Córdoba, 14-21 Octubre 1985), Córdoba, Diputación, 1987, edición de G. Carnero.

7. Ver mi «Modernismo frente a noventa y ocho: The case of Juan Ramón Jiménez (1899-1909)", apud P. Gómez Bedate (ed.), Estudios sobre Juan Ramón Jiménez, Recinto Universitario de Mayagüez, Puerto Rico, 1981, 119-41 y «Myths Ancient and Modern: Modernismo frente a noventayocho and the Search for Spain", apud. R.A. 
En el campo, y especialmente en las montañas (con referencia tras referencia a su Obermann querido y con ecos de Senancour y $\mathrm{Amiel}^{8}$ ) descubre una nueva armonía entre el panorama del gran mundo ante su vista, el cielo encima y su propio ser. En el mismo ensayo, "El silencio de las cumbres», propone tal simbiosis:

\begin{abstract}
Allí, a solas con la montaña, volvía mi vista espiritual de las cumbres de aquélla a las cumbres de mi alma, y de las llanuras que a nuestros pies se tendían a las llanuras de mi espíritu. Y era forzosamente un examen de conciencia. El sol de la cumbre nos ilumina los más escondidos repliegues del corazón. (616)
\end{abstract}

Estas palabras tienen ecos de los escritores románticos norteuropeos y también de las experiencias de Francisco Giner. La frase «examen de conciencia» suena al idioma autocrítico y autocontemplativo de los krausistas. En este ensayo y en "Frente a los negrillos" se nota un parentesco extraordinario con Giner, Ortega y Jiménez en cuanto a una experiencia trascendental. Tal experiencia, no cabe duda, se puede denominar religiosa o mística. Pero lo que busca no es la divinidad, a pesar de las muchas referencias a lo divino, sino eternidad y permanencia, una estructura básica que yace dentro de lo visible, "la imagen» (618).

Más adelante apunta que siente «la inmovilidad en medio de las mudanzas, la eternidad debajo del tiempo" y, en un eco más del tema intrahistórico que ya había desarrollado en En torno más de un lustro antes, dice que puede tocar "el fondo del mar de la vida" (622). Es un tema que ya hemos comentado. En su fuga de la metrópolis y en su busca de una recreación espiritual en la naturaleza y el campo sigue Unamuno la tradición de los románticos norteños de hace más de un siglọ y, más próximamente, de los hombres de la Institución Libre y «los modernos». El excursionismo, pues, tiene un atractivo personal y fuerte; es la señal exterior de una busca intensamente personal de sí mismo. Como en Azorín, Jiménez, Machado y otros, las preocupaciones más destacadas son el deseo de huir, un enriquecimiento espiritual, un anhelo de algo mejor, más allá, con lo cual se pueda sentir

Cardwell (ed.), Essays in Honour of Robert Brian Tate from his Colleagues and Pupils, University of Nottingham Monographs in the Humanities, II, 1984, 9-21.

8. Será interesante establecer cuánto influyó el estilo de estos dos escritores en las evocaciones de Unamuno; es decir, establecer si su descripción es más bien documental e individual o, como sugiero, poética y basada en fuentes literarias. Propongo investigar este tema en adelante en otro estudio. Y no hace falta olvidar tampoco lo profunda que fue la atracción hacia Amiel sentida por Juan Ramón Jiménez. 
una armonía, un sentido de permanencia; su sentido de la inevitabilidad de la vida a pesar de sus deseos; de ahí su insatisfacción con el presente, con la muchedumbre y la ciudad, con el tedio del contacto social cotidiano. Son aspectos estudiados por Ramsden en su edición de La ruta y The 1898 Movement (esp. la sección 5: "The Quest for Self») y en los estudios míos (nota 7). Y también otro sentimiento que es preciso notar: su sentido del fluir inexorable del tiempo y su nostalgia por un pasado en que la vida le pareció mejor, más permanente. Son humores, sentimientos y anhelos comunes entre los escritores del fin de siglo en España. Y la evocación unamunesca de estos humores es muy parecida a la de ellos. Consideremos, por ejemplo, esta descripción (mejor evocación) de las ruinas del monasterio cisterciense de la Granja de Moreruela:

¿Qué majestad de aquella columnata de la girola que se abre hoy al sol, al viento y a las lluvias! ¡Qué encanto el de aquel ábside! ¡Y qué intensa melancolía la de aquella nave tupida hoy de escombros sobre la que brota la verde maleza! Y todo ello se alza, añorando siglos que fueron, y quién sabe si siglos por venir, en un valle de sosiego y de olvido del mundo. (1911: 633)

Como sus contemporáneos, encuentra Unamuno una satisfacción curiosa cuando se comunica con su dolor y su melancolía (aquí sobrepuestos a la realidad) y los transmuta diestramente en un sentimiento de belleza, de tranquilidad y calma emocional, los cuales sugieren otra forma de permanencia. Es casi como si las ruinas tuvieran un espíritu interior eterno. Hizo constar esta convicción más de una vez, como en su ensayo sobre Salamanca cuando habla de "una cierta vida espiritual» (1914: 725).

Esta alma «subterránea» presente, en la interpretación científica que impone Unamuno, es el espíritu de las fuerzas de la causalidad determinista. Pero también es un tipo de panteísmo romántico y, combinado con el sentido de las fuerzas evolutivas, se hace referencia al panteísmo krausista. Quizás, también, se encuentre una veta estética en la misma herencia porque la espiritualidad unamunesca tiene una decidida inclinación en esta dirección:

Emprendí esta peregrinación artística [a Guadalupe] apenas terminé mi curso universitario [...] buscando unos días de reposo y de baño en naturaleza para poder volver con renovadas fuerzas [...]. Y hoy llevo, en el relicario de mis recuerdos, un recuerdo más, un recuerdo perfumado y fresco, el de la bravía verdura de Guadalupe. (477)

Volveremos enseguida sobre esto del «relicario de mis recuer- 
dos». Más tarde, en 1916, afirmó el profesor salmantino, «esto de as. cender a las cimas de las montañas [...] es un placer que tiene tanto de sensual como de estético" (786). Si esto nos recuerda a Amiel o a Giner de los Ríos, la frecuente combinación de lo sensual con lo estético, como en esta evocación de Mallorca, nos recuerda a los modernistas y Rubén Darío: «se puede penetrar en la belleza espiritual de la isla de oro, en lo que quiere decir aquella fantasía divina encarnada en roca florecida y ceñida por el mar de zafiro y de esmeraldas y de topacios y de nácares irisados" (791). La veta determinista se nota cuándo Unamuno relacionó este paisaje con la poesía de Ramón Llull, literatura como producto del medio ambiente. Pero el determinismo -la busca de estructuras fundamentales y eternas- y la adoración de la belleza y la lengua poética finisecular -también una busca de estructuras interiores en el pozo de la imaginación-se juntan en este comentario:

Sediento contemplabả una vez las espesuras del Zarzoso que se tiende al pie de la Peña de Francia, [...] y aunque la angustia - iy era grande!me privara de mirarlas con el sosiego que la contemplación exige, nunca comprendí mejor su metáfora. (843)

Aquí vemos la tendencia modernista a buscar la contemplación estética como alivio de la angustia metafísica ${ }^{9}$. En 1902, Juan Ramón, quizás más auto-conscientemente esteta, evocó su estado espiritual en estos términos simbolista-decadentes:

Me llenan de una dulce melancolia esos rincones de jardín de hospital [...]

Cuando viene cayendo la tarde, y en la yerba dorada y trasparente tienden los árboles las sombras alargadas de sus troncos [...] por todo el jardín flota [...] una serenidad que nos hace pensar en los muertos... ${ }^{10}$.

Más austeramente y evitando los lugares comunes del simbolismo finisecular -jardín, señales de muerte, etc.- evoca Unamuno un paisaje no menos poético, ni menos espejo del humor del propio escritor $^{11}$; Unamuno evoca su vida interior, su propia personalidad

9. Ver D.L. Shaw, «Modernismo: A Contribution to the Debate», BHS, XLIV 1967, 195-202 y mis «Dario and El Arte Puro: The Enigma of Life and the Beguilement of Art», BHS, XLIV, 1970, 37-51 y Juan R. Jiménez: The Modernist Apprenticeship (1895-1900), Berlin, Colloquium Verlag, 1977.

10. Libros de prosa, Aguilar, Madrid, 1969, 75 (PLP). Siempre cito por esta edición.

11. Y no se deben olvidar las evocaciones casi «modernistas" -y seguramente de tono 
proyectándose sobre sus realidades recordadas, un viaje al Escorial en 1912:

Luego... el Adaja, el río de Avila, que ofrece de pronto una rinconada de melancólico recogimiento, y al transmontar una cuesta, las murallas de Olmedo y sus torres derritiéndose en la luz del atardecer. (1912: 636)

Es, como admitió abiertamente en el prólogo a sus Andanzas, un "paisaje literario», y además añadió: «A esta demanda de la afición estética es a lo que quiere responder la oferta de este libro". Sus descripciones excursionistas tienen muy poco de lo documental, de lo realista: "No puedo evitar el ponerme en mis escritos" (720); “¿Datos? ¿Qué es eso de datos? ¿Te figuras que habría de ser una historia documentada?» (1900: 66). Lo que destaca en estos escritos, como en la obra de sus contemporáneos y el testimonio de su contacto con los campos de Castilla -Machado, Ortega, Baroja, Azorín, aun Juan Ramón- es el elemento lírico y poético, la preocupación por la belleza austera de España después del momento simbolista y sus jardines y parques decadentes:

Eso de hablar de la aridez repulsiva de El Escorial, como hablar de lo sombrío de su carácter, carece, en rigor, de valor estético, pues falta probar que lo árido y lo sombrio no puedan ser hermosísimos [...]. Y debo confesar que a mí me produce una más honda y fuerte impresión estética la contemplación del páramo, sobre todo a la hora de la puesta del sol. (1912: 643-44)

Quizás no sea una coincidencia que en el mismo momento de evocar tal paisaje árido con su aureola de luz dorada fuera Machado a publicar sus Campos de Castilla, donde encontramos paisajes parecidos. Ni hay que olvidar las evocaciones de Azorín -especialmente La ruta de don Quijote y Castilla- ni las de Baroja-Camino de perfección-ni las de Jiménez-Pastorales-. En estas evocaciones del paisaje español bañado en una luz crepuscular y dorada encontramos los persistentes ecos del simbolismo francés pero también la veta determinista combinada con una recreación mediante el arte de una realidad recordada para siempre, una realidad transmutada líricamente sugiriendo no sólo la belleza sino también la permanencia, la eternidad. El amor y apego a la tierra-Machado y Soria, Unamuno y La Fle-

profundamente estético finisecular-en "Puesta de sol» que apareció en Revista Nueva, I, 13 (15-VI-1899) y "Fantasía crepuscular», Vida Nueva, 14-VIII-1898, ambos en O.C., I, 71-76 y $77-80$. 
cha, Ortega y el valle del Duero, Azorín y la Mancha, Juan Ramón y Moguer o los Pirineos, también Maragall y el Montseny- se muestran en toda una generación. Así que las excursiones de estos escritores no son solamente una respuesta a las necesidades espirituales o emocionales, son también una necesidad estética. Finalmente son una busca de una estructura; estructura revelada por las ciencias deterministas o estructura revelada por medio de una exploración de la imaginación poética y la memoria, las galerías del alma o los ensueños de un Machado o un Juan Ramón. No necesitan una realidad porque, en última instancia, prefieren "el cristal de la mente» o "el relicario de mis recuerdos» (Unamuno), «una cueva de ensueño» (Jiménez), «las galerías del alma» "el profundo espejo de mis sueños» (Machado). Como pregunta Azorín:

¿Para qué hacer el viaje? Hay un momento en la vida en que descubrimos que la imagen de la realidad es mejor que la realidad misma [...]. Sólo nos queda, en lo íntimo del espíritu, su imagen. Una imagen fugaz, como la de un sueño: una imagen de algo que queremos recordar y no recordamos [...]. (III, 594-5)

Se encuentra el mismo énfasis en un ensayo temprano de Unamuno, "Brianzuelo de la Sierra. Notas de viaje», donde se ve que prefiere el autor su visión anticipada a la realidad futura. Llegó tarde al pueblo y se puso a dormir. «Y aquel sueño, aquel sueño profundo y tranquilo es el recuerdo más puro y más hondo que de Brianzuelo de la Sierra conservo». Por eso no quiere contacto con la realidad a la mañana siguiente: "¿Pues a qué hemos venido? / -iA soñarlo! Déjame que me le figure a mi antojo..." (1900: 63-64). El sueño antes que la realidad, «fondos» previstos en la imaginación; temas obsesivos.

Hemos visto, pues, las estrechas relaciones que existen en las parecidas respuestas líricas y emocionales frente al problema psicológico general en toda una generación. Aquí, por lo tanto, sería apropiado aplicarme de nuevo al muy debatido problema del «Modernismo frente a Noventayocho" y la separación -para mí completamente arbitraria- de la generación finisecular en dos grupos. El profesor Ramsden ha insistido en que mientras los hombres de esta generación compartieron todos un dilema básicamente romántico, una crisis de fe, encontraron soluciones distintas: los modernistas en la torre de marfil del Arte, los hombres del 98 en la realidad y en el determinismo. Pero, ¿hubo tal diferencia? He sostenido en los estudios citados (nota 7) que hace falta poner este argumento, y especialmente la tesis de Díaz-Plaja en tela de juicio. Aquí considero brevemente, 
como prolegómeno de un estudio más amplio, el caso de Unamuno frente a (o mejor, en) este grupo.

No es dudoso que uno de los temas más destacados en la literatura finisecular fue el tema de la memoria y el ensueño, y destacó singularmente en España: «Estoy solo, tengo sueño [...] / Los recuerdos se amontonan en mi mente» (Jiménez, 1902); "Y podrás conocerte, / recordando del pasado soñar / los turbios lienzos, / [...] / De toda le memoria, sólo vale / el don preclaro de evocar los sueños" (Machado, 1907); "Del pasado dichoso sólo podemos conservar el recuerdo" (Azorín, 1912); "Amar el pasado es congratularse de que efectivamente haya pasado, y de que las cosas, perdiendo esta rudeza con que al hallarse presente arañan nuestros ojos, nuestros oídos y nuestras manos, asciendan a la vida más pura y esencial que llevan en la reminiscencia" (Ortega, 1911). Ahora escuchemos a Unamuno: "Lo que hay que ver no es la visión presente; lo que hay que ver es su recuerdo, su imagen" (I, 842); "Todo imaginar y hasta conocer [...] es un recordar»; "Al evocar mi recuerdo dormido en el hondón de mi memoria, de lo que era el campo de Albia en lo que hoy es el ensanche de Bilbao, brotóme él a flor de alma en forma rítmica, en versos de meditación poética, de eso que los lakistas ingleses llamaban musings» («Visiones rítmicas»). Estas expresiones nos recuerdan no solamente la imaginación romántica de la Europa del norte y la herencia del simbolismo sino también el interés de los modernistas por este tema. La última expresión unamunesca tiene ecos tanto de Juan Ramón como de la crítica de Gregorio Martínez Sierra y su La vida inquieta.

Hasta ahora se encuentra una tendencia crítica a excluir a Unamuno del grupo modernista. y se sigue insistiendo en tal punto a pesar de la afirmación juanramoniana de que, por los años del fin de siglo, se le llamó a Unamuno «ese tío modernista». No quiero decir que fue Unamuno un escritor torremarfileño como Darío o Villaespesa; sí quiero sugerir que hace falta poner en tela de juicio el uso del término modernista (o Modernismo) y su enfrentamiento con el Noventayocho. Hemos encontrado toda una serie de coincidencias curiosas entre los autores finiseculares de ambos supuestos grupos, especialmente en el proceso de auto-contemplación y la manera en la que se transmutan las realidades recordadas en arte; también en la ideología o el idealismo en que esta visión se basa.

Por los años de 1890 los escritores jóvenes han vuelto la espalda a la conmemoración de los ideales nacionales y la conciliación cívica. 
La crítica no dejó de notar este cambio ${ }^{12}$. Según estos comentaristas el escepticismo y una visión fragmentada del mundo llevan a una busca dentro del hombre de un núcleo no fragmentado; la autocontemplación es auto-descubrimiento, la búsqueda de raíces, pero es, al mismo tiempo, un medio hacia un nuevo ideal absoluto. También, como he sugerido, la idea de una fuerza latente determinista que da una estructura eterna debajo de la realidad misma tomó parte en este desarrollo idealista, especialmente por su autoridad científica. Por estos años, y no olvidando sus orígenes en el romanticismo, se formó una nueva concepción de la facultad imaginativa, el ser interior de la inconsciencia; el arte moderno (modernista) es la expresión exterior de esta actividad auto-contemplativa y mentalmente intelectúalizada. Las experiencias de la realidad (el sentimiento y, luego, la memoria) pasan por un proceso de trasmutación en el crisol interior de la imaginación (de ahí palabras como cristal, relicario, espejo) para revelar no sólo la belleza o el valor de la circunstancia, los accidentes del momento, sino también su valor eterno, su belleza sin tiempo. Revelan también ideas, conceptos o estructuras preexistentes, y así también eternos. Es este el ideal del arte finisecular del que se encuentra una expresión definitiva en el poema introductorio de las $\mathrm{Ga}^{-}$ lerías machadianas.

Escuchemos ahora a Unamuno en su ensayo clave, "Frente a los negrillos» (quizás el ensayo más trascendente de las Andanzas):

Y la vista del escaramujo [...] me recuerda el más dulce y vivificante re-
cuerdo de una obra propia, y más si ésta es de poesia: el de su parto. Es
que nuestras mejores y más propias ideas, molla de nuestro espíritu,
nos vienen, como de fruta alimenticia, de la visión del mundo que tene-
mos delante, aunque luego, con los jugos de la lógica, la transformemos
en quimo ideal, de que sacamos el quilo que nos sustenta. (1915: 738)

12. En comentario tras comentario se nota un tema común: «[El poeta] suspenso el ánimo en medio del fragoroso conflicto de ideas [...] vuelve sobre sí propio e imagina que hallará [...] [dentro] la paz y la armonía" (F. Giner de los Ríos, 1865); "Pues hay dentro de la vida del arte mucho [...] de nuestra vida interna" (F.A. de Icaza, 1894); «...El progreso mental ha hecho que el sentido estético se intelectualice [sic] [...]. Pretenden también los modernistas remozar el fondo psicológico de la poesía [...]. No deja de ser resbaladizo este terreno de la nueva psiquis, y es muy explicable que algunos de los modernistas se deslicen en sus Psicologismos [...]. Su asunto principal es el sentimiento inconsciente de nuestro ser...» (E. Gómez de Baquero, 1902); "La obsesión del subjetivismo [...] arrastra a los modernistas, víctimas de la contemplación propia, a la investigación de lo absoluto [...]. Oscilan entre su escepticismo [...] y un misticismo cerebral" (V. González Serrano, 1903); «Las emociones intelectuales, he dicho, son las emociones contemporáneas» (G. Martínez Sierra, 1905). 
A pesar del juego de palabras unamunesco entre el sentido biológico (lo físico), simbólico (interior espiritual) y popular («sudar el quilo") se encuentra aquí un proceso que se ve en la poesía finisecular a partir de Bécquer y los precursores modernistas (Gil e Icaza) hasta el grupo Helios y aun Ortega; es decir, un énfasis sobre ensueño y memoria como alivio y como consecuencia de la vacuidad de la vida. Todo lo que queda como consolación son los recuerdos distantes y nostálgicos de tiempos más felices o de acción (reales o imaginados), recuerdos no degenerados de la infancia (significadamenté asociados con la luz dorada del crepúsculo, las campanas de la parroquia, el hogar y el pueblo), recuerdos de momentos pasados de satisfacción emocional o espiritual profunda. Agobiados por el fracaso vital y la desilusión, elevan frente a su pérdida la autenticidad de su propio dolor. Y de su dolor y su auto-contemplación se levanta un estado mental especial. El silencio y la soledad, especialmente en los rincones de las ciudades antiguas o en el campo, les ofrecen atractivo. Y su soledad es menos opresiva cuando pueden evocar un pasado más feliz, una memoria recreada interiormente. Así la niñez, la adolescencia o el pasado de una España más grande, se ven como temas obsesionantes en la literatura de este grupo. Visita Azorín el aula de su colegio en Las confesiones de un pequeño filósofo; evoca Machado los patios y galerías sevillanos; en Moguer, narra Juan Ramón, "el alma dormita por dentro, cansada y aterida, soñando con el oro de la infancia» (1903: PLP, 71) y, allí, el sol sugiere "añoranzas de rincones dorados, con el eco de las voces lejanas de una aldea" (1903: PLP, 92). A su vez estos autores evocan, como lo hace Unamuno, el pueblo natal y los sonidos de la vida cotidiana. ¿Por qué? He investigado la veta determinista del interés por el campo y por el pueblo. También he subrayado el tema del fluir del tiempo. Es un aspecto que ha analizado Ramsden (HR, 180-81). ¿Hubo otra forma de escape para Unamuno? Creo que sí, forma que se encontrará también entre sus contemporáneos. El viajar para Machado fue un tipo especial de "sueño» y para Ortega y Baroja, Pérez de Ayala o Juan Ramón el contacto con la naturaleza puede administrar el ambiente necesario para una experiencia "mística». Pero también, sugiero que la común busca del «alma» de España (hayan estado profundamente afectados estos autores por las filosofías evolucionistas o no) en el "pueblo anónimo" se vio ligada con su preocupación por el proceso mental y artístico de reproducir sus experiencias en un tipo de diario intimo, diario que fueron los ensayos, poemas o novelas excursionistas de esta generación. Unamuno estuvo constantemente preocupado por este proceso y con fre- 
cuencia se refiere a su cuaderno o a sus reacciones más íntimas en el momento de creación. Su preocupación por encontrar estructuras subyacentes deterministas se transfirió a ahondar en el proceso imaginativo de darles testimonio. Es cuestión de transmutar la experiencia sensorial de la realidad en algo más allá de lo temporal, buscar, como afirmó en "Paisaje Teresiano", "la metáfora". "Lo que hay que ver no es la visión presente; lo que hay que ver es su recuerdo, su imagen" (842). De ahí que, como sugiere Machado o Juan Ramón, la memoria no sea sencillamente un modo de recordar, sino, a la vez, un modo de reconocer arquetipos preexistents o estructuras eternas. Casi como los poetas modernistas del grupo Helios (incluso Ortega) admite Unamuno lo siguiente:

$\mathrm{Y}$ al decir que todo pintor pinta de memoria no nos referimos al tiempo que pasa desde que mira al modelo hasta que tiene que mirar al papel o lienzo en que traza su imagen, ino! Este es un aspecto demasiado primario y superficial de la cosa. Es que el artista pinta la imagen que recibe del objeto presente y esta imagen es un recuerdo siempre, hasta cuando ve por primera vez el recuerdo. Todo imaginar y hasta conocer -lo sabía ya Platón- es un recordari. Y todo recuerdo es una metáfora. [...]. La metáfora es el fundamento de la conciencia de lo eterno. (842)

Y termina este ensayo afirmando la unión de lo estético con lo metafísico. En una fecha tan temprana como 1899 parece que Unamuno había formulado una visión platónica del mundo, base del simbolismo europeo. Entre su descripción de las nubes crepusculares como «islas de apacible quietud en la región de los ensueños" y "perfume de luz" (con ecos del esteticismo finisecular) y exclamaciones de tono plenamente "modernista» (“iCeleste revelación de las entrañas de la belleza misma, del divino esplendor de la forma pura iluminada...!» (71-73)), lucha con el problema de una lengua adecuada y desarrolla el tema de estructura dentro de estructura o formas espejeadas (jugando con forma y formosus):

:Ah! ¡Si pudiera repercutir aquella sublime sinfonía celestial de pocas y preñadas notas de purísimos colores de fuego y de cándidos perfiles! ¿Si pudiese pintarla para siempre y no tener que verter aquí el rastrojo que de aquellas feraces momentos ha quedado en la tumba de mi memoria! En un insondable seno de la divina Conciencia vive el eco de aquella celestial sinfonía, y en el seno de mi conciencia dormirá su reflejo, que yace tan adentro, tan adentro de ella, que de sacarlo no hay arte alguno [...]. La celeste visión era entonces lo real y fuerte, y el terrestre campo, nuestro sostén, mezquino remedo de ella... (I, 72)

¿No es ésta la base del arte de Bécquer y, más claramente, la del de Juan Ramón Jiménez? 
También, como hemos visto, la infancia (con todos sus recuerdos y visiones no deterioradas de ilusiones y contento) fue un tema muy explorado por los escritores finiseculares. A Unamuno sus excursiones le llevaron al campo, al contacto con el "pueblo anónimo". Pero también le suministraron un sentido de libertad, de huída de una realidad fastidiosa, de regreso a tiempos de su infancia. (1911: 610)

Y en el párrafo siguiente continúa para ampliar su pregunta retórica: «Y en estas correrías por campos y montes, iqué alivio, qué hondo sentimiento de libertad radical cuando dejando todo decoro se pone uno a hacer y decir chiquilladas!... Se chapuza uno en la infancia» (611). Y de modo más revelador añade:

¡Oh, estas sumersiones en la remota infancia! No sé cómo puede vivir quien no lleve a flor de alma los recuerdos de su niñez. Trece volúmenes llevo yo publicados, pero de todos ellos no pienso volver a leer sino uno, el de mis Recuerdos de niñez y mocedad, donde, en días de serenidad ya algo lejana, traté de fijar no mi alma de niño, sino el alma de la niñez.

No la realidad temporal y lógica sino la estructura arquetípica subyacente de la imaginación ilógica. Un subtítulo apropiado para sus Recuerdos, sugirió Unamuno, pudiera haber sido "ensayo de psicología de la infancia". Ahora bien, hemos visto que la palabra "psicología" y sus derivaciones y analogías fueron palabras clave entre los intelectuales finiseculares; palabràs como alma, genio, voluntad, carácter, sueño, soñar, etc., se usaron como lengua común en la crítica y en el arte de entonces ${ }^{13}$. En una carta, hablando de Paz en la guerra (1897) Unamuno ha sostenido la tesis de que en la lengua puede uno encontrar "el reflejo más fiel de la psicología del pueblo» ${ }^{14}$. He sugerido antes que quizás exista un eslabón entre la busca de un núcleo en el campo y en el pueblo anónimo y la busca de lo que llamó Machado "una verdad divina» que yacía "en el profundo / espejo de mis sueños" (LXI, Galerias). También he subrayado la preocupación por

13. Ver, por ejemplo, esta crítica de las Arias tristes de Jiménez: «Para él no hay en el mundo comedias ni tragedias, porque a la actividad pensante de su espíritu no puede dársele con exactitud nombre de pensamiento ni de sentimiento; quisiera yo hallar apelación apropiada a esta maravillosa facultad suya, que no sé si reside en el intelecto o en el corazón, y que es virtud penetrativa, [...] escudriñadora [...]; actividad que tiene campo exclusivo de acción en lo delicado, $[. .$.$] no ya de los hechos ni de$ las cosas, sino del alma de estas cosas y de estos hechos", G. Martínez Sierra, La Lectura, IV, I, 1904, 343-44.

14. En carta a Pedro de Mugica, Cartas inéditas de Miguel de Unamuno, Santiago de Chile, Zig-zag, 1965, 100. 
la lengua poética. Cuando escribió Machado, "Podrás conocerte, recordando / del pasado soñar los turbios lienzos" (LXXXIX), habla de un doble proceso, el auto-conocimiento (es decir, auto-contemplación o auto-descubrimiento) y la busca de la otredad (ideal o arquetipo). De la misma manera se busca Unamuno a sí mismo en el ensueño, lo que llaman los krausistas "un examen de conciencia", en este estado especial de la mente (casi místico) que testimoniaron tantos escritores y comentaristas, a menudo invocando o refiriéndose a San Juan de la Cruz, San Francisco o Santo Tomás de Kempis, todos autores favoritos del grupo Helios, de la Institución Libre y, claro, de Unamuno. En la cumbre de una montaña considera el profesor salmantino los posibles caminos que pudiera haber seguido en su vida:

Allí, en la cima, envuelto en el silencio, soñaba en todos los que, habiendo podido ser, no he sido para poder ser el que soy; soñaba en todas las posibilidades que he dejado perder desde aquella infantil atracción al claustro... (1911: I, 618)

Siente remordimiento pero también percibe, como los simbolistas, "el inevitable destino». "Y da fuerzas, da fuerzas como una sumersión en la fuente de la vida", añadió. Su ensueño le trae la percepción de lo permanente:

Está aquello como estaba hace un siglo, hace dos, hace cuatro, hace veinte. Es la imagen viva de lo inalterable. (618)

¿Por qué? La metáfora -la estructura arquetípica deseada, el núcleo, la imagen que es, al mismo tiempo, parte de la realidad percibida y recordada y transmutada mediante el arte - se ha revelado al profesor salmantino. En parte es una estructura espiritual yacente preexistente, en parte, la belleza manifiesta en forma de imagen viva y eterna; lo que, en otra parte, llama Unamuno el "sentimiento estético de la naturaleza" (1909: 592-93), sentimiento que describe significativamente, como "moderno» y "de origen romántico». También su imaginación o su mente "reflexiona sobre éste y [lo] eleva a idea" (1915: 737). En sus descripciones de su contacto con algo más allá, de la unión con el elemento espiritual de las cumbres, en fin, de un arrobo casi místico, vemos cuán cerca se encuentra la experiencia artística y la auto-proyección de Unamuno del idealismo de Azorín, de Mar tínez Sierra o de Juan Ramón. En La voluntad (1902), Yuste afirma:

Lo que da la medida de un artista es su sentimiento de la naturaleza, del paisaje [...]. Un artista será tanto más artista cuando mejor sepa interpretar la emoción del paisaje [...]. Es una emoción completamente, casi completamente moderna. 
Gregorio Martínez Sierra, en su interesante estudio Motivos (1905), describió estos momentos trascendentales en términos muy parecidos a Unamuno o a otros de la generación, especialmente cuando da énfasis al deleite y al placer de la experiencia:

Busca el espíritu la perfección y da con ella, y entonces surge una nueva voluptuosidad, antaño sólo conocida de místicos y filósofos, la voluptuosidad del intelecto en presencia del fin adecuado, del filósofo en presencia de la verdad, del místico ante la esencia divina. (28)

Repite los mismos sentimientos en La vida inquieta (Glosario espiritual) de 1913. Al mismo tiempo, Unamuno no supo dejar atrás su sentido de estructuras físicas, o. mejor, la estructura determinista que se manifiesta en el medio ambiente. Por esta razón se encuentra la típica mezcla unamuniana del lenguaje de las ciencias (especialmente las biológicas) con el del espíritu interior y la memoria o el ensueño:

Aquellos paisajes que fueron la primera leche de nuestra alma, aquellas montañas, valles o llanuras en que se amamantó nuestro espíritu cuando aún no hablaba, todo eso nos acompaña hasta la muerte y forma el meollo, el tuétano de los huesos del alma misma. Porque ésta tiene su esqueleto [...] para quien tiene alma vertebrada, con huesos que la mantengan en pie y mirando al cielo, esos huesos se nutren de un tuétano que está hecho con las serenas y nobles visiones de la niñez lejana. (1911: 626)

No es solamente que el hombre esté determinado física y espiritualmente por el medio ambiente en el cual nació y se crió. Es como si, también, su manera de recordar, de sentir, de reproducir sus sensaciones lo fuese moldeando imborrablemente. Esta matriz queda inalterable dentro del hombre mientras viva y le servirá de núcleo. Y como para los simbolistas, la imagen es anterior a la lengua y se escapa de ella. Viajar, dice Unamuno, es sentir más profundamente las propias raíces. Pero también, como para los llamados modernistas, es captar, mediante el ensueño, la memoria y la lengua insuficiente del arte, las esencias eternas; recrea por medio del prisma de la obra las realidades recordadas, "elevarlas a,idea».

Sería posible seguir más adelante en este argumento para señalar no solamente la veta simbolista en la preocupación por encontrar un lenguaje adecuado, expresar "ausencias" y confirmar un núcleo (lo que llamó Machado «una verdad divina») sino también subrayar la obsesión por lo que quede en la memoria («el sueño sustancial») y por asir un fragmento de eternidad. Aunque no debemos olvidar la veta 
determinista y el aspecto posromántico que se han discutido en los primeros párrafos de este estudio (aspectos vinculados a todo esto) me parece que la preocupación insistente por indagar "la metáfora", "la imagen" y "el relicario de los recuerdos" ubica a Unamuno claramente entre las preocupaciones estéticas y metafísicas de un Juan Ramón, un Antonio Machado, un Ortega o un Azorín.

Si quisiéramos comprender a fondo el arte de los escritores finiseculares, los "modernos", sería tiempo ya de descartar divisiones críticas artificiales y teorías simplistas de enfrentamiento para concentrarnos sobre el arte mismo y lo que dice esta generación en sus poesías, sus novelas y sus ensayos. Un análisis de la literatura excursionista me parece un excelente punto de partida. 